\title{
ДИДАКТИЧЕСКАЯ ИГРА КАК СРЕДСТВО АКТИВИЗАЦИИ ПОЗНАВАТЕЛЬНОЙ ДЕЯТЕЛЬНОСТИ МЛАДШИХ ШКОЛЬНИКОВ НА УРОКАХ ОКРУЖАЮЩЕГО МИРА
}

\section{DIDACTIC GAMES AS A MEANS OF ACTIVATING COGNITIVE ACTIVITY IN PRIMARY SCHOOL STUDENTS IN THE CLASSROOM OF THE SURROUNDING WORLD}

\section{R. Mirzayanova}

L. Mamedova

Summary: In modern educational practice, teachers are increasingly faced with the problem of selecting the best methods, techniques and types of work to activate the cognitive activity of students, which in turn is very important in the formation of a versatile personality from the very first days of school. To solve this problem, we conducted a study on the basis of MBOU SOSH No. 15 in Neryungri. The study was aimed at determining the level of formation of cognitive activity, as well as students ' interest in conducting didactic games in the classroom of the surrounding world, which in turn would allow us to justify the importance of using this method of work as one of the most effective means of activating the cognitive activity of primary school students in the classroom of the surrounding world. The study involved students of class $2 B$ in the number of 24 people. The complex diagnostics that we used helped us to identify the level of cognitive activity of students, as well as the importance of using didactic games in activating cognitive activity in the classroom of the surrounding world.

Keywords: didactic game, level of formation, cognitive activity, cognitive activity, surrounding world.
Мирзаянова Рената Рустемовна
Технический институт (филиал) Северо-Восточный
федеральный университет имени М.К. Аммосова, федеральный университет имени М.К. Аммосова,
2. Нерюнгри

mirrenru14@inbox.ru

Мамедова Лариса Викторовна

К.п.н., дочент, Технический институт (филиал) СевероВосточный федеральный университет имени М.К. Аммосова, г. Нерюнгри larisamamedova@yandex.ru

Аннотация: В современной образовательной практике учителя все чаще сталкиваются с проблемой подбора оптимальных методов, приемов и видов работы для активизации познавательной деятельности учащихся, которая в свою очередь является очень значимой при формировании разносторонне развитой личности с самых первых дней обучения в школе. Для решения данной проблемы нами было проведено исследование на базе МБОУ СОШ №15 в г. Нерюнгри. Исследование было направлено на определение уровня сформированности познавательной активности, а также заинтересованности учениками в проведении дидактических игр на уроках окружающего мира, что в свою очередь позволило бы нам дать обоснование значимости использования данного метода работы как одного из самых эффективных средств активизации познавательной деятельности учеников начальной школы на уроках окружающего мира. В исследовании приняли участие ученики $2 \mathrm{~B}$ класса в количестве 24 человек. Комплексная диагностика, которую мы использовали, помогла нам выявить уровень познавательной активности учеников, а также значимость использования дидактических игр в активизации познавательной деятельности на уроках окружающего мира.

Ключевые слова: дидактические игры, уровень сформированности, познавательная деятельность, познавательная активность, окружающий мир.
A ктуальность выбранной темы исследования обуславливается тем, что в современной образовательной системе большое внимание уделяется познавательной деятельности как одной из ведущих форм деятельности ребенка, которая так или иначе сказывается на развитии его личности и служит основой для прочного построения фундамента из знаний, подкрепленных различными умениями и навыками.

Активизация познавательной деятельности выступает в качестве одной из первостепенных задач, решаемых педагогом начальных классов на протяжении всего периода четырехлетнего обучения.

Показательнее всего познавательная активность и деятельность в начальной школе проявляется на уро- ках окружающего мира. На данный момент это является одной из насущных проблем, а именно - низкая заинтересованность в данном предмете со стороны обучающихся, с которой сталкивается учитель. Для ее решения до сих пор ведутся поиски новых эффективных методов обучения, способных заинтересовывать учащихся не только пользоваться готовыми знаниями, но также и самостоятельно добывать новые. В первые годы обучения одними из самых эффективных методов по праву являются дидактические игры.

В ФГОС НОО второго поколения предмет «Окружающий мир» рассматривается как часть системы начального образования, а значит, он призван решать не только частные, но и общие задачи начальной школы. Общие требования к результатам освоения программы курса 
занятий по предмету «Окружающий мир» отражают основную идею данного исследования: активизация познавательной деятельности способствует формированию устойчивого интереса к изучаемому предмету, как следствие учит добывать и использовать знания, путем применения различных способов деятельности, а также устанавливать причинно-следственные связи в окружающем мире [5 с. 13].

Как писал советский педагог В.А. Сухомлинский «В игре раскрывается перед детьми мир, раскрываются творческие способности личности. Без игры нет и не может быть полноценного умственного развития» [4, с. 33]. Рассмотрев различные научные труды, нами было установлено, что изучением активизации познавательной деятельности путем использования дидактических игр занимались следующие педагоги и психологи: Ю.К. Бабанский, Е.В. Бондаревская, Л.С. Выготский, Г.И Щукина. В последние годы теоретическими и практическими вопросами применения дидактических игр в учебной практике занимались такие исследователи, как: А.П. Усова, Е.И. Радина, Ф.Н. Блехер, Б.И. Хачапуридзе, 3.М. Богуславская, Е.Ф. Иваницкой, А.И. Сорокина.

Анализируя вышеизложенную информацию, можно сделать вывод, что проблема активизации познавательной деятельности у учеников начальных классов рассматривалась и рассматривается достаточно подробно. Однако цель нашего исследования - определение уровня сформированности познавательной активности, а также заинтересованности учениками в проведении дидактических игр на уроках окружающего мира.

По результатам данного исследования можно будет дать обоснование значимости использования дидактических игр для активизации познавательной деятельности младших школьников на уроках окружающего мира.

Исследование проводилось на базе МБОУ СОШ №15 г. Нерюнгри у учеников 2В класса.

Для того, чтобы составить комплексную диагностику, в ходе проведения исследования нами было задействована методика «Оценка уровня познавательной активности», разработанная учителем начальных классов Авдошиной А.Ф. на основе опросника Ч.Д. Спилбергера [1], а также анкетный опросник «Выявление отношения детей к игре на уроке» [3, с. 45].

На первом этапе работы нами была проведена диагностика по методике А.Ф. Авдошиной «Оценка уровня познавательной активности», где уровень познавательной активности младших школьников определялся по пятибальной шкале, путем вывода среднего балла по всем ответам на вопросы.
Высокий уровень - 4,0 - 5 баллов

Средний уровень - 3,0 - 3,9 балла

Низкий уровень - 2,5 - 2,9 балла

При обработке данных подсчитывались баллы, и выводилось среднее значение для каждого младшего школьника в отдельности, затем выводилось среднее значение по испытуемой группе. В Таблице 1 представлены результаты младших школьников по уровням познавательной активности, которые были распределены в соответствии со шкалой.

По полученным результатам, отраженным в таблице 1. средний балл оценки познавательной активности младших школьников составил 4,2 - это достаточно высокий показатель, который свидетельствует о том, что ученики 2В класса отличаются не только стремлением к изучению нового материала, но и заинтересованностью в установлении взаимосвязей между различными явлениями. Однако если рассматривать каждую группу отдельно, то можно увидеть, что 5 учеников показывают средний и 3 низкий уровень познавательной активности. Эти показатели несколько отличаются от предыдущего, говоря нам, что ученики хоть и пытаются понять, запомнить и воспроизвести знания, но их препятствие характеризуется неустойчивостью волевых усилий, отсутствием интереса к углублению знаний и вопросов по типу «Почему?».

Следующим этапом нашего исследования было проведение анкетирования среди учеников с целью выяснить их отношение к применению дидактических игр на уроках.

Анкета «Выявление отношения детей к игре на уроке» состоит из пяти вопросов, на каждый их которых ученикам предлагается выбрать один из трех вариантов ответа.

В ходе анкетирования были получены следующие данные (таблицы 2, 3, 4, 5, 6).

По результатам ответов на данный вопрос из общего количества учеников - 24 (100\%) 18 (75\%) предпочитают уроки, в которые включены различные дидактические игры, 3 (15\%) ученика считают, что на уроке должно быть интересно вне зависимости от выбранных видов работы, оставшиеся 2 (10\%) ученика выбирают работу, не связанную с активной игровой деятельностью, предпочитая изучать материал с использованием схем, таблиц и наглядного материала.

Таким образом, больше половины детей от общей выборки - 14 (60\%) отмечают желание принимать участие в играх на уроках, однако нельзя не заметить, что при ответе на этот вопрос $40 \%$ учеников (6 (25\% и 3 (15\%) со- 
Таблица 1.

Результаты оценки познавательной активности младших школьников

\begin{tabular}{|c|c|c|c|c|c|}
\hline \multirow[b]{2}{*}{ Школа } & \multirow[b]{2}{*}{ Класс } & \multirow{2}{*}{$\begin{array}{c}\text { Количество } \\
\text { учеников классе }\end{array}$} & \multicolumn{3}{|c|}{ Количество учеников, показавших } \\
\hline & & & $\begin{array}{c}\text { 4,0-5 баллов } \\
\text { (высокий уровень) }\end{array}$ & $\begin{array}{c}\text { 3,0-3,9 баллов } \\
\text { (средний уровень) }\end{array}$ & $\begin{array}{c}\text { 2,5 - 2,9 балла } \\
\text { (низкий уровень) }\end{array}$ \\
\hline МБОУ СОШ №15 & $2 B$ & 24 & 16 & 5 & 3 \\
\hline \multicolumn{3}{|c|}{ 0бщий уровень в группе } & \multicolumn{3}{|c|}{4,2} \\
\hline
\end{tabular}

Таблица 2.

Какие уроки ты больше всего любишь?

\begin{tabular}{|c|c|c|c|}
\hline Урок & $\begin{array}{c}\text { главное, чтобы было } \\
\text { интересно }\end{array}$ & $\begin{array}{c}\text { с использованием игр } \\
\text { сисользованием схем, } \\
\text { таблиц и рисунков }\end{array}$ \\
\hline Кол-во выборов в \% & $15 \%$ & $75 \%$ & $10 \%$ \\
\hline
\end{tabular}

Таблица 3.

Если бы ты был учителем, чего больше было бы у тебя на уроке?

\begin{tabular}{|c|c|c|c|}
\hline Приемы работы & использование игр & работа с учебником & таблицы, схемы, рисунки \\
\hline Кол-во выборов в \% & $60 \%$ & $25 \%$ & $15 \%$ \\
\hline
\end{tabular}

Таблица 4.

Как часто в вашем классе на уроках окружающего мира бывают игры?

\begin{tabular}{|c|c|c|c|}
\hline Частота применения & не очень часто & часто & очень часто \\
\hline Кол-во выборов в \% & $20 \%$ & $54 \%$ & $26 \%$ \\
\hline
\end{tabular}

Как ты относишься к игре на уроке окружающего мира?

\begin{tabular}{|c|c|c|c|}
\hline Отношение & очень хочется участвовать & $\begin{array}{c}\text { нет большого желания } \\
\text { поддерживать игру }\end{array}$ & $\begin{array}{c}\text { игра на уроке - пустая трата } \\
\text { времени }\end{array}$ \\
\hline Кол-во выборов в \% & $75 \%$ & $25 \%$ & - \\
\hline
\end{tabular}

Таблица 6.

Как ты думаешь, какая польза от игры на уроке окружающего мира?

\begin{tabular}{|c|c|c|c|}
\hline Отношение & очень большая & большая & нет пользы \\
\hline Кол-во выборов в \% & $75 \%$ & $25 \%$ & - \\
\hline
\end{tabular}

ответственно) выбрали традиционные приемы работы при изучении как нового материла, так и повторении пройденного.

Анализируя ответы на данный вопрос можно сделать вывод, что чуть больше половины учеников - 13 (54\%) отмечают частое использование игр на уроках. Это можно объяснить тем, что наиболее эффективным средством включения ребенка в процесс творчества на уроке является игровая деятельность. Стоит учесть и то, что исследование проводилось в первый месяц первой четверти 2 класса, поэтому ответы учеников на этот вопрос основывались в своем большинстве на опыте предыдущих четвертей 1 класса.

Таким образом, большинство детей из общей выборки - 18 (75\%) положительно относятся к участию в раз- личных играх, проводимых учителем. Остальные 6 (25\%) учеников не проявляют большего желания поддерживать игру. Также никто из учеников, вне зависимости от отношения к игре, не считают ее пустой тратой времени на уроке.

Как можно заметить, результаты остались теми же, что и в ответе на предыдущий вопрос. Многие дети видят пользу в использовании игр, также эта положительная динамика была отмечена при проведении данного опроса. Большинство детей очень активно включаются в деятельность, которая требует от них быстрой реакции, сообразительности и принятия самостоятельных решений.

Также в дополнение к данному вопросу мы решили провести небольшой устный опрос, где ученики долж- 
ны были поочередно назвать, какую именно пользу приносит использование дидактических игр на уроках окружающего мира. Ответы учеников были проанализированы, обобщены и распределены по трем главным показателям результативности:

1. «игры повышают познавательный интерес» - 14 (58\%);

2. «игры помогают лучше узнать окружающий мир» 7 (29\%);

3. «игры помогают лучше запоминать новый материал»- 3 (12\%).

Из результатов диагностики можно сделать вывод, что учащиеся начальной школы положительно относятся к использованию дидактических игр. Основная масса учеников видит в этом практическую значимость, а нами было отмечено, что использование дидактических игр оказывает большое влияние на активизацию познавательной деятельности учащихся на уроках окружающего мира.

После проведенного исследования нами был сделан вывод, что дидактическая игра - это сложное, многогранное явление. «В дидактических играх происходит не только усвоение учебных знаний, умений и навыков, но и развиваются все психические процессы у детей, их эмоционально-волевая сфера, способности и умения» $[2$, c. 7]. Умелое использование игры в учебном процессе заметно облегчит его, так как игровая деятельность привычна для ребенка. Через игру быстрее познаются закономерности обучения. Положительные эмоции значительно облегчают процесс познания.

Подводя итоги нашего исследования, можно сказать, что ценность дидактических игр заключается в том, что в процессе игры дети в значительной мере самостоятельно приобретают новые знания, активно помогают друг другу в этом. Игра побуждает учащихся к игровым действиям, даёт возможность каждому ребёнку лучше представить разыгрываемую ситуацию. «В игре дети учатся концентрировать свое внимание на игровых правилах и следить за их выполнением. Игра позволяет ребёнку заново пережить яркие впечатления и события» [6, с. 7]. В процессе использования дидактической игры на уроках окружающего мира у обучающихся развивается познавательный интерес, т.е. у младших школьников появляется, желание учится, узнавать, что - то новое, самим добывать знания.

Статья выполнена под руководством научного руководителя: к.п.н., доцента Мамедовой Л.В.

\section{ЛИТЕРАТУРА}

1. Авдошина Н.Ф. Диагностические мероприятия по определению уровня познавательной активности младших школьников. - 2017. - 8 с.

2. Глущенко Л.В. Использование дидактической игры в процессе обучения младших школьников. - 2014. - 9 с.

3. Лунегова Ж.С. Активизация познавательной деятельности младших школьников посредством использования дидактических игр. - 2013. - 52 с.

4. Сухомлинский В.А. Сердце отдаю детям.- Киев: Радянська школа, 1974 г. - 288 с.

5. Федеральный государственный образовательный стандарт начального общего образования. - М.: Просвещение, 2010. - 29 с. (Стандарты второго поколения)

6. Шибаева И.А. Дидактические игры как средство формирования познавательного интереса детей младшего школьного возраста. Методическая разработка. $-2016 .-48$ c.

(c) Мирзаянова Рената Рустемовна (mirrenru14@inbox.ru), Мамедова Лариса Викторовна (larisamamedova@yandex.ru).

Журнал «Современная наука: актуальные проблемы теории и практики» 